www.arpnjournals.com

\title{
THE SELF COMPACTING CONCRETE (SCC) USING SEAWATER AS MIXING WATER WITHOUT CURING
}

\author{
Erniati Bachtiar \\ Departmentof Civil Engineering, Faculty of Engineering, Fajar University, Makassar, Indonesia \\ E-Mail: erni_nurzaman@yahoo.com
}

\begin{abstract}
The number of problems found in the construction world include the difficulty or lack of fresh water in some areas to be mixed in the concrete, negligence in the maintenance of concrete and working process of concrete mainly on the concrete structures have a complex reinforcement and high concrete building structures. This study aims to find out the compressive strength, splitting tensile strength, absorption, and porosity of Self Compacting Concrete (SCC) using sea water as mixing water and with or without curing in sea water. The test specimens were made for each test specimen with the variation on age 1 day, 3 days, 7 days, 28 days and 90 days. The test method of compressive strength according to ASTM 39/C 39M-12a standard, tensile strength according to ASTM C496 / C496M-11 standard and the porosity and absorption according to ASTM C642-13 standard. The result of research was 1) the decrease in compressive strength in the specimen SCC-SWC was from 3 days, 7 days, 28 days and 90 days consecutive $13.20 \%, 12.90 \%, 12.80 \%$, and 12.50\%; 2) the decreases in splitting tensile strength in the specimen SCC-SWC were from the age of 3 days, 7 days, 28 days until the age of 90 days consecutive by $3.10 \%, 8.05 \%, 9.51 \%$, and $9.21 \%$; 3 ) the increase in the porosity values on the specimen SCC seawater without cured in sea water (SCC-SWC) at age 3 days, 7 days, 28 days and 90 days was $2.86 \%, 7.90 \%$, $5.86 \%$, and $5.55 \%$, respectively; 4 ) the increase in the absorption values on the specimen SCC without curing at 3 days, 7 days, 28 days and 90 days was $15.80 \%, 20.57 \%, 15.84 \%$, and $30.80 \%$, respectively. The increase in mechanical properties (compressive strength and tensile strength) in the both of the specimen SCC-SC and SCC-SWC along with the decrease of porosity and absorption. Conversely, the decrease of compressive strength and tensile strength in the both of the specimen SCC-SC and SCC-SWC along with the increase in porosity and absorption value in the SCC.
\end{abstract}

Keyword: SCC, seawater, curing, compressive strength, splitting tensile strength, absorption, porosity.

\section{INTRODUCTION}

The development of today's concrete technology is very rapid. The innovative research was done by researchers to get something new as an effort to improve the quality of concrete emerging. The researchers have done many researchs to answer the problems that arise from the use of materials in concrete mixing and overcome the constraints that often occur to the implementation of work in the field. The problems found in the construction world are the difficult areas of clean water to be used as concrete mixing water, concrete workability, and concrete work processes, especially concrete structures that have complex reinforcement, high concrete structure, and negligence in the maintenance of concrete.

Skilled workers needed for requires the adequate compaction in the creation of durable concrete structures. However, the reduction quantity of skilled workers in Japan's construction industry has led to a similar reduction in the quality of construction work. One solution for the performance of concrete structures durable depends on the quality of construction work is the implementation of selfcompacting concrete (SCC). The SCC can be compacted into every corner of a formwork purely by its own weight and without the need for vibrating compaction (Okamura and Ouchi, 2003)[10]. The SCC concrete can flow with its own weight, than it easier to work on concrete especially on structures using complex reinforcement, and so that SCC fresh can flow and fill every empty space of the mold(EFNARC, 2005)[5]. Fresh Concrete SCC has the high fluidity that can flow and fill the spaces in the mold with little or no vibration process and reduce the compaction process time then to high fluidity that fresh concrete can be lifted and carried easily through the pump to a high level on the mount flooring as well as on structures that have very solid reinforcement (Okamura and Ouchi, 2003).

Otsuki et al. (2012), explain in the paper that the mixing of sea water on concrete using Blast-Furnace Slag Cement (BFS) produces Friedel's salt and total pore volume decreased as well as increased strength compared with fresh water [11]. Research conducted by Erniati (2014, 2015a) on SCC used fresh water and seawater as water mixing and cured of concrete. In her research has examined the workability, compressive strength, and microstructure of SCC. From the results of her research, the increase in compressive strength of SCC using sea water and fresh water experienced the most significant difference at the early age i.e. age 1 and 3 days. This occurs that the sea water accelerates the formation of Tobermorite (CSH) then the bond matrix with aggregate is stronger. In addition, the Friedel's salt formed fills the pores than the micro structure were denser. Increased microstructural density was in line with increasing compressive strength as well as decreasing pore size and porosity (Erniati et al., 2014, 2015a) [7,8].

This study was part of previous research on SCC that uses sea water as mixing water. Problems of the field that often happen are negligence in the implementation cured of concrete, so then the quality of the plan was not matched. This research is part of the previous research about SCC using sea water as mixing water and cured with sea water (Erniati et al., 2014, 2015a; Erniati et al., 
www.arpnjournals.com

2015b). The aims of these researches were to know the mechanical properties of SCC using sea water as mixing water and with or without cure in sea water (Curing) $[7,8,9]$.

\section{RESEARCH METHODS}

\section{A. Materials}

In the research used some material. They were cement type Portland Composite Cement (PCC), fresh water, seawater, local crushed stone (size maximum 20 $\mathrm{mm}$ ), local sand (size maximum 4.75) and super plasticizer

\section{B. The design}

The research method used is experimental method. The research was conducted in the laboratory. The design self-compacting concrete (SCC) used the method of European Federation of Specialist Chemical Concrete Construction Systems (EFNARC, 2005)[5]. The mix design of SCC used water cement volume of 1,1 .

\section{The experimental}

All the ingredients were mixed with 3 stages. First, fine sand and coarse aggregate in condition Saturated Surface Dry (SSD), then mixed together for \pm 1 min. Second, the cement is inserted into the machine concrete mixer containing aggregate; the mixing is done about 1-2 minutes. Third, after a homogeneous mixture, the water was mixed super plasticizer incorporated into the concrete, and mixing about 2-3 minutes and the mixture is considered in concrete mixer to ensure a homogeneous mixture. Then the mixture is ready to be tested slump flow and T50. After the measurements and observations, where it meets the requirements of the SCC is then inserted into the cylinder size of $10 \times 20 \mathrm{~mm}$. The sample is made of 15 cylinders for each of the 3 samples. The test specimen is tested performed before treatment for 1, 3, 7, 28 and 90 days.

Test of Slump flow and T50 is the test to determine the viscosity of SCC without any obstructions. By knowing the workability and slump flow indication filling ability of SCC can be known. The T50 time is also a measure of flow rate and viscosity of the SCC. This test uses the slump cone and plate as shown in Figure 1. The middle of the plate, there should be a line of $500 \mathrm{~mm}$ diameter circle has a centre that coincides with the midpoint of the plate.

The mixing of SCC concrete is done after the aggregate test either coarse or fine aggregate according to American Society for Testing Material (ASTM) standard $[1,2,3]$. After the results of the constituent material test are eligible, then mix design with EFNARC method [5].

Materials and tools were prepared which all used in mix of SCC. All the ingredients were mixed with 3 stages. First, coarse aggregate and fine sand in condition Saturated Surface Dry (SSD) mixed together for $\pm 1 \mathrm{~min}$. Second, the cement was inserted into the machine concrete mixer containing aggregate; the mixing is done about 1-2 minutes. Third, after a homogeneous mixture, the water was mixed super plasticizer incorporated into the concrete, and mixing about 2-3 minutes and the mixture is considered in concrete mixer to ensure a homogeneous mixture. Before fresh concrete is formed into the mold, first test workability is done. Test workability aims to determine whether the fresh concrete meets the standards as SCC as the EFNARC standard. The sample of compressive strength is cylindrical in size $10 \mathrm{~mm} \times 20$ $\mathrm{mm}$. The specimen SCC were used seawater as mixing water and curing named SCC-SC, while the specimen SCC were used seawater as a mixing water without cured in seawater named SCC-SWC.

There are two mechanical tests of this research that is compressive strength and tensile. Compressive strength and splitting tensile strength were performed at 1 day, 3 days, 7 days, 28 days and 90 days with 3 samples respectively. Than the porosity tested at 3 days, 7 days, 28 days and 90 days.

Standard test method for Compressive strength follows the ASTM 39/C 39M - 99 [1]. Equipment Universal Testing Machine (UTM) is used to test the compressive strength by providing static monotonic uniaxial compressive load at an average speed of 0.14 to $0.34 \mathrm{MPa} / \mathrm{Sec}$. Calculate the compressive strength of cylindrical specimens as follow equation (1).

$f^{\prime}{ }_{c}=\frac{P}{A}$

Where f'c $=$ concrete compressive strength $(\mathrm{MPa}), \mathrm{P}=$ Peak load $(\mathrm{N}), \mathrm{A}=$ surface area of the cylinder $(\mathrm{mm})$.

Splitting tensile strength testing method follows the ASTM C496/C496M-11 [2]. Calculate the splitting tensile strength of the specimen as follows equation (2).

$T=\frac{2 \mathrm{P}}{\pi \mathrm{LD}}$

Where $\mathrm{T}=$ splitting tensile strength, $\mathrm{MPa}, \mathrm{P}=$ maximum applied load indicated by the testing machine $(\mathrm{N}), \mathrm{L}=$ length, $\mathrm{mm}$ and $\mathrm{D}=$ diameter $(\mathrm{mm})$.

Porosity and absorption test were using ASTM C642-13 standard [3]. Porosity and absorption can be calculated by the following equation (3) and (4).

$e=\frac{B-A}{B-C_{i b}} \times 100$

$a=\frac{\left(C_{i}-A\right)}{A} \times 100 \%$

Where $\mathrm{e}=$ porosity of the concrete, $\mathrm{A}=$ mass of ovendried sample in air, B = mass of surface-dry sample in air after immersion and boiling (g), Cib = mass of sample in water after immersion and boiling $(\mathrm{g}), \mathrm{Ci}=$ mass of sample in water after immersion $(\mathrm{g})$.

\section{RESULT AND DISCUSSIONS}

A. Compressive strength and splitting tensile strength 
www.arpnjournals.com

This research, workability both the fresh state of SCC using fresh water or sea water qualifies as SCC.

The compressive strength was the most mechanical properties in the quality of concrete compared with other properties. The compressive strength was determined by calculation of the ratio comparison cement, coarse and fine aggregates, water and various mixtures. The cement water ratio is a major factor in determining the strength of concrete. The lower the cement water ratio, the higher the strength of concrete. However, excess water improves the ability of ease in the work of concrete (workability) but lowers the strength of concrete. Application of the SCC concrete technology, then the small cement water ratio will obtain a high compressive strength with good workability. This paper does not explain the results of SCC workability using sea water as mixing water and curing, because that discussed in the previous paper by (Erniati et al., 2015a)[8]. In the paper, concluded that SCC sea water has eligible workability as SCC as per EFNARC standard.

The result of this research was the compressive strength of SCC using seawater as mixing water and curing to attain the target of quality concrete compressive strength in suitable with the plan $\geq 50 \mathrm{MPa}$, then on the specimen SCC without curing in sea water (SCC-SWC) at 28 days is compressive strength a decrease of $12.79 \%$ and splitting tensile strength a decrease of $9.51 \%$ of the planned target. The result of SCC study of sea water with and without curing in sea water on the relationship between compressive strength with the age of concrete is illustrated as in Figure-1, then SCC study of sea water with and without curing in sea water on the relationship between splitting tensile strength with the age of concrete is illustrated as in Figure-2.

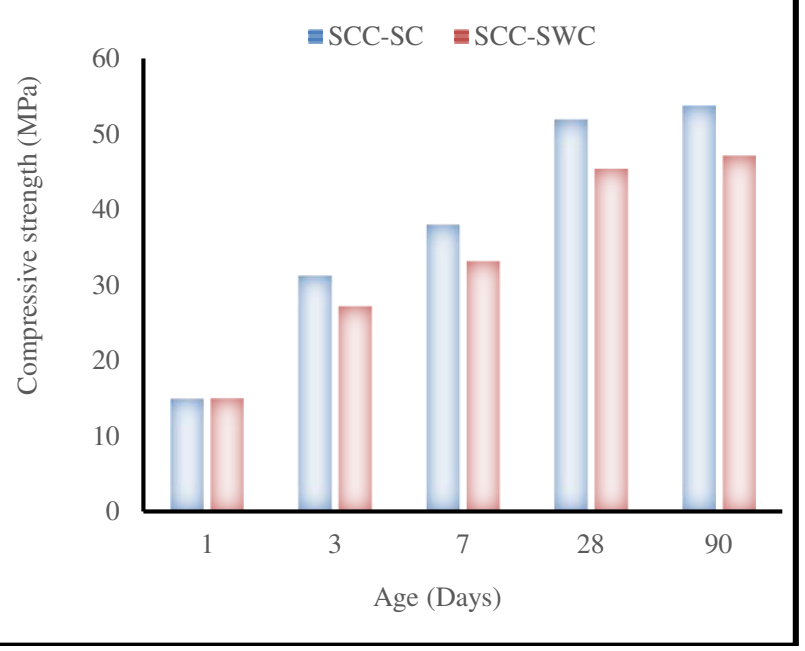

Figure-1. The compressive strength SCC-SC and SCC-SWC.

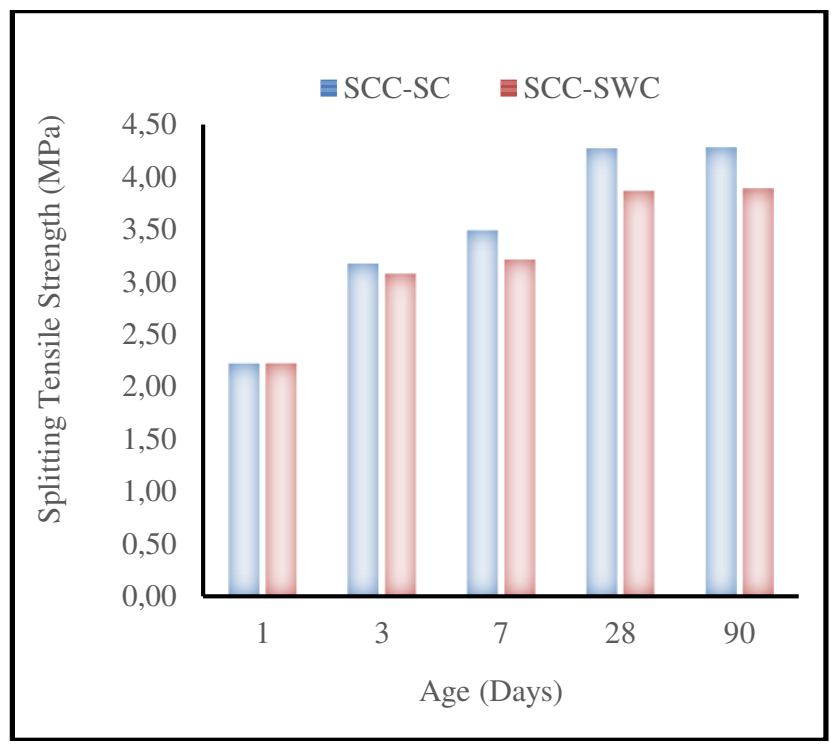

Figure-2. The splitting tensile strength on both SCC-SC and SCC-WC.

Figure-1 shows the compressive strength relationship with age on SCC sea water with and without curing in sea water (SCC-SC and SCC-SWC), where the compressive strength on both in SCC-SC and SCC-WC were increases with age. Besides, it is shown in Figure-1, the decrease of compressive strength in SCC-SWC since age 3 days, 7 days, 28 days up to age 90 days were consecutively $13.2 \%, 12.9 \%, 12.8 \%, 12.5 \%$ of the compressive strength SCC-SC.

Figure-2 shows the splitting tensile strength relationship with age on SCC sea water with and without curing in sea water (SCC-SC and SCC-SWC), where the splitting tensile strength on both in SCC-SC and SCC-WC were increases with age. Besides, it is shown in Figure-1, the decrease of the splitting tensile strength in SCC-SWC since age 3 days, 7 days, 28 days up to age 90 days were consecutively $3.10 \%, 8.05 \%, 9.51 \%, 9.21 \%$ to the splitting tensile strength SCC-SC.

Figure-1 and Figure-2 also show that the compressive strength were increases with age of concrete. The decrease in compressive strength and tensile strength occur in concrete if not cured in concrete, as previous studies of characteristics SCC used fresh water without curing, with the result of a decrease the strength of concrete if the concrete is not cured (Erniati, 2016)[6]

\section{B. The porosity and absorption}

Result testing of porosity and absorption on both SCC-SC and SCC-SWC can be seen Figure-3 and Figure4. 
www.arpnjournals.com

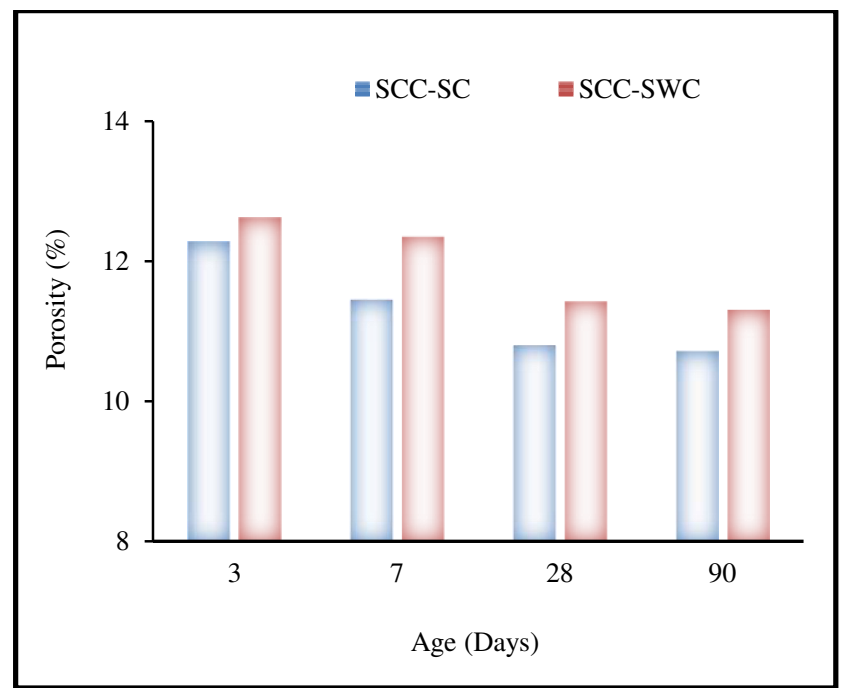

Figure-3. The porosity of SCC-SC and SCC-SWC.

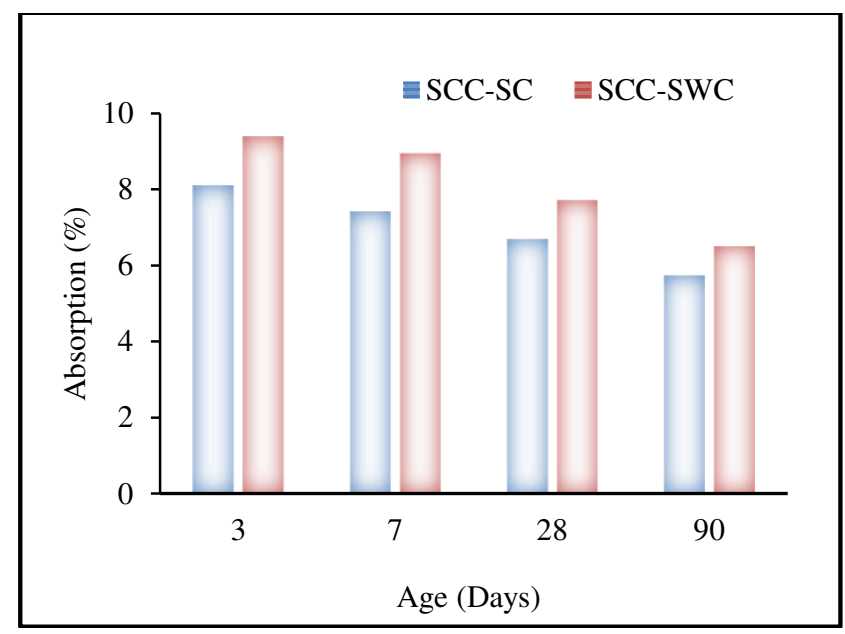

Figure-4. The absorption of SCC-SC and SCC-SWC.

Figure-3 shows the relationship between porosity value and age in both the sample SCC-SC and SCC-SWC. The porosity value decreases with increasing with age of concrete. Beside that the comparison between porosity values of both SCC-SC and SCC-WC, i.e. porosity value of SCC-SWC is higher than SCC-SC. The increase of porosity value if not cured at 3 days, 7, days, 28 days and 90 days was $2.86 \%, 7.90 \%, 5.86 \%, 5.55 \%$, respectively.

Figure-4 shows the relationship between absorption value and age in both the sample SCC-SC and SCC-SWC. The absorption value decreases with increasing with age of concrete. Beside that the comparison between absorption values of both SCC-SC and SCC-WC, i.e. absorption value of SCC-SWC is higher than SCC-SC. The increase of absorption value if not cured at 3 days, 7, days, 28 days and 90 days was $15.80 \%$, $20.57 \%, 15.84 \%, 30.80 \%$, respectively.

\section{Relationship between compressive strength, tensile strength, porosity and absorption}

The decrease that occurs in both compressive strength and tensile strength in SCC-SWC was caused by the non-optimal hydration process. This was strongly supported with the both of porosity and absorption values on SCC-SCW samples higher than SCC-SC samples. Thus it was concluded that the density is not maximal on the sample SCC-SWC. As the result of research by Tjaronge et al. (2014) has been researching on the concrete using sea water and sea sand as concrete material, with the result of research that the concrete was not cured, it will undergo less optimal hydration process [12]. Previous research by (Erniati et al., 2015a)that the hydration process in the optimal concrete is high concrete density, low concrete porosity, and matrix bonds or solid concrete microstructure [8]. Conversely, if the hydration process is not optimal then the bond matrix or microstructure is not solid then the strength of concrete decreases [8]. (Chen et al. (2013)) has examined mortar with the result that porosity affected the compressive strength and tensile strength of mortar [4].

From the research and discussion on the compressive strength, splitting tensile strength, absorption and porosity it is concluded that the increase of mechanical properties (compressive strength and tensile strength) in the both of SCC-SC and SCC-SWC along with the decrease of porosity and absorption. Conversely, the decrease of compressive strength and tensile strength in the both of SCC-SC and SCC-SWC along with the increase of porosity and absorption value in concrete.

\section{CONCLUSIONS}

The decrease in compressive strength in the specimen SCC-SWC was from 3 days, 7 days, 28 days and 90 days consecutive $13.2 \%, 12.9 \%, 12.8 \%$, and $12.5 \%$. The decreases in splitting tensile strength in the specimen SCC-SWC were from the age of 3 days, 7 days, and 28 days until the age of 90 days consecutive by $3.10 \%$, $8.05 \%, 9.51 \%$, and $9.21 \%$. The increase in the porosity values on the specimen SCC seawater without cured in sea water (SCC-SWC) at age 3 days, 7 days, 28 days and 90 days was $2.86 \%, 7.90 \%, 5.86 \%$, and $5.55 \%$, respectively. The increase in the absorption values on the specimen SCC without curing at 3 days, 7 days, 28 days and 90 days was $15.80 \%, 20.57 \%, 15.84 \%$, and $30.80 \%$, respectively. The increase in mechanical properties (compressive strength and tensile strength) in the both of the specimen SCC-SC and SCC-SWC along with the decrease of porosity and absorption. Conversely, the decrease of compressive strength and tensile strength in the both of the specimen SCC-SC and SCC-SWC along with the increase in porosity and absorption value in the $\mathrm{SCC}$

\section{REFERENCES}

[1] ASTM C39/C39M - 12a, Standard Test Method for Compressive Strength of Cylindrical Concrete Specimens, October 2012.

[2] ASTM C496/C496M-11, 2011 Standard Test Method for Splitting Tensile Strength of Cylindrical Concrete Specimen, August 2011. 
[3] ASTM C 642 - 06, Standard Test Method for Density, Absorption, and Voids in Hardened Concrete, August, 2006

[4] Chen X., S. Wu and J. Zhou. 2013. Influence of Porosity on Compressive and Tensile Strength of Cement Mortar. Construction and Building Materials. 40:869-874.

[5] EFNARC, 2005. The European Guidelines for Self Compacting Concrete. UK. www.efnarc.org.

[6] E Bachtiar, 2016. Characteristic of Self Compacting concrete without Curing. Journal of Techno Entrepreneur Acta, 1(2), 143-148 (Indonesia)

[7] E Bachtiar, MW Tjaronge, R Djamaluddin, V Sampebulu. 2014. Microstructure Characteristics of Self Compacting Concrete using Sea Water. International Journal of Applied Engineering Research. 9(22): 18087-18095.

[8] E Bachtiar, MW Tjaronge, R Djamaluddin,V Sampebulu. 2015a. Compressive Strength and Slump Flow of Self Compacting Concrete Uses Fresh Water and Sea Water. ARPN Journal of Engineering and Applied Science. 10(6): 2373-2377.

[9] E Bachtiar, MW Tjaronge, Zulharnah, UR Arfan. 2015b. Porosity, Pore Size and Compressive Strength of Self Compacting Concrete Using Sea Water. Procedia Engineering, 125: 832-837.

[10] Okamura H. and M. Ouchi. 2003. Self Compacting Concrete, Journal of Advanced Concrete Technology. $1(5-15)$.

[11] Otsuki N., T. Saito and Y. Tadokoro. 2012. Possibility of Sea Water as Mixing Water in Concrete. Journal of Civil Engineering and Architecture. 6(10): 12731279.

[12] M.W. Tjaronge, R. Irmawaty, S. A. Adisasmita, A. Amiruddin, and Hartini. 2014. Compressive Strength and Hydration Process of Self Compacting Concrete (SCC) Mixed with Seawater, Marine Sand, and Portland Composite Cement. Advanced Materials Research. 935: 242-246.

[13] Wegian F. M. 2010. Effect of seawater for mixing and curing on structural concrete. The IES Journal Part A: Civil \& Structural Engineering. 3(4): 235-2. 